\title{
Retraction Note: Rainfall forecast and computer data algorithm optimization in coastal areas based on improved neural network
}

\author{
Jingzhu $\mathrm{Wu}^{1} \cdot$ Xiuzhi Xing ${ }^{2}$ \\ Published online: 4 January 2022 \\ C) Saudi Society for Geosciences 2022
}

Retraction Note: Arabian Journal of Geosciences (2021) 14:1-17

https://doi.org/10.1007/s12517-021-07579-1

The Editor-in-Chief and the Publisher have retracted this article because the content of this article is nonsensical. The peer review process was not carried out in accordance with the Publisher's peer review policy. The authors have not responded to correspondence regarding this retraction.

The original article can be found online at https://doi.org/10.1007/ s12517-021-07579-1.

Jingzhu Wu

zhujingwu2007@163.com

1 Center for Teaching and Learning Development, Zhoukou Normal University, Zhoukou 466001, China

2 Department of Mathematics, Zhoukou Normal University, Zhoukou 466001, China 